\title{
Prevención farmacológica de reacciones anafilácticas serias debidas a medios de contraste iodados
}

\author{
Pharmacological prevention of serious anaphylactic reactions due to iodinated contrast media
}

Tramer MR y col. BMJ 2006; 333:675

\section{Objetivo}

Evaluar la eficacia de la prevención farmacológica de reacciones anafilácticas serias debidas a medios de contraste iodados.

\section{Fuente y selección de datos}

Búsqueda amplia en Medline, Oldmedline, Embase, HealthSTAR, CINAHL, Cochrane entre 1950 y 2005 y de las referencias de los artículos encontrados.

\section{Extracción de datos}

De los 64 trabajos potencialmente relevantes, nueve (10.011 pacientes totales) cumplieron los criterios de inclusión (asignación aleatoria, premedicación sola o combinada, grupo control con o sin placebo, referencia de la presencia o ausencia de reacciones alérgicas). Fueron evaluados por un investigador y validados por otros. Un alergista y un anestesista decidieron para cada síntoma la probabilidad de que fuera de origen alérgico y definieron los de riesgo de vida. Los criterios de exclusión no se especificaron en seis trabajos y en los tres restantes fueron el haber incluido pacientes con antecedente de reacciones a medios de contraste iodados o historia de alergia, atopía o hipersensibilidad.

\section{Resultados principales}

Ninguno trabajo incluyó exclusivamente pacientes con historia de reacciones alérgicas. No se encontraron reportes de muerte, resucitación cardiopulmonar, daño neurológico irreversible o internaciones prolongadas.

El $0,4 \%(3 / 778)$ de los pacientes premeditados con corticoides tuvo edema laríngeo vs. el 1,4\% (11/769) de los controles (OR:
0,31; IC95\% 0,11 a 0,88). Ninguno de los primeros tuvo hipotensión vs. $0,4 \%$ de los controles (OR: 0,14; IC 95\% 0,01 a 1,30$)$.

La incidencia de síntomas respiratorios (tres trabajos) fue de $1 \%$ en quienes habían recibido antihistamínicos y de $2,3 \%$ en sus controles (OR: 0,46; IC95\% 0,15 a 1,39); y de 0,4\% en el grupo esteroides en comparación con $1,4 \%$ de sus controles (OR: 0,31; IC95\% 0,11 a 0,88).

En quienes recibieron la combinación clemastina-cimetidina la incidencia fue $0,5 \%$ en comparación con $4,1 \%$ de los controles (OR: 0,20; IC95\% 0,05 a 0,76).

Los síntomas cutáneos (seis trabajos) se presentaron en el $2 \%$ de los pacientes que habían recibido antihistamínicos en comparación con $6,1 \%$ de los controles (OR: 0,36; IC95\% 0,22 a 0,60 ) y en el $0,6 \%$ de los asignados a esteroides en comparación con $2 \%$ de los controles (OR: 0,36; IC95\% 0,15 a 0,87).

\section{Conclusiones}

Las reacciones anafilácticas serias luego de la administración de medios de contraste iodados parecen ser muy raras. La utilidad de la premedicación es dudosa en pacientes no seleccionados, ya que debe administrarse a un número muy grande de pacientes para obtener beneficio. No hay datos de estudios en pacientes con historia de reacciones alérgicas.

Palabras clave: alergia, medios de contraste, prevención. Key words: alergia, contrast media, prevention.

\section{Comentario}

La administración de medios de contraste iodado es una práctica habitual y la duda acerca de si vale la pena premedicar a todos los pacientes o sólo a aquellos con antecedentes de reacciones alérgicas en particular, es también habitual. La presente revisión sistemática intenta responder la primera de ellas. Las reacciones alérgicas serias son muy raras, y no hay evidencia clara de que se reduzcan con la premedicación. Algunos hallazgos del presente trabajo permiten concluir que la premedicación con esteroides disminuye la incidencia de síntomas respiratorios y hemodinámicos. Los antihistamínicos evidenciaron una reducción en el riesgo de aparición de síntomas cutáneos; mientras que la asociación clemastina-cimetidina previno el angioedema en un trabajo y en un limitado número de pacientes.

Sin embargo, ninguno de estos trabajos incluyó pacientes con historia de reacciones alérgicas exclusivamente, se refirieron a una amplia variedad de síntomas y la interpretación de cuáles fueron de origen alérgico no es clara. Por otro lado, los medios de contraste utilizados en la actualidad -de baja osmolaridadpresentan una menor tasa de reacciones adversas moderadas, lo que implicaría que la utilidad de la premedicación pudiese ser menor. Otras limitaciones metodológicas son la inadecuada aleatorización o ausencia de ceguera en algunos casos. Es importante destacar que hasta la fecha no se conocen exactamente los mecanismos responsables de las reacciones adversas por contrastes iodados, siendo universalmente aceptado que no obedecerían a mecanismos inmunológicos y que no existirían métodos predictivos útiles.

\section{Conclusiones del comentador}

Cuando existe la indicación de un estudio contrastado es importante la evaluación de cada paciente en particular, la categorización de su riesgo y la definición de la indicación o no de premedicación, así como la utilización de medios de contraste de alta o baja osmolaridad.

Roxana Haas [ Sección Alergia del Hospital Italiano de Buenos Aires ]

Haas R. Prevención farmacológica de reacciones anafilácticas serias debidas a medios de contraste iodados. Evid. actual. práct. ambul; 10(4):103 JulAgo.2007. Comentado de: Tramer MR, von Elm E, Loubeyre P, Hauser C. Pharmacological prevention of serious anaphylactic reactions due to iodinated contrast media: systematic review. BMJ 2006 Sep 30; 333(7570):675. PMID: 16880193.

\section{Referencia}

1. Colodenco D, et al. Reacciones adversas a los medios de contraste radiológicos. Criterios y conductas. Asociación Argentina de Alergia e Inmunología Clínica y Sociedad Argentina de Radiología.

2. Morcos S, et al. Prevention of generalized reactions to contrast media: a consensus report and guidelines. Eur Radiol. 2001. 11: 1720-1728.

3. Greenberger $\mathrm{P}$, et al. The prevention of immediate generalized reactions to radiocontrast media in high risk patients. J Allergy Clin Immunol. 1991. 87: 867-872. 